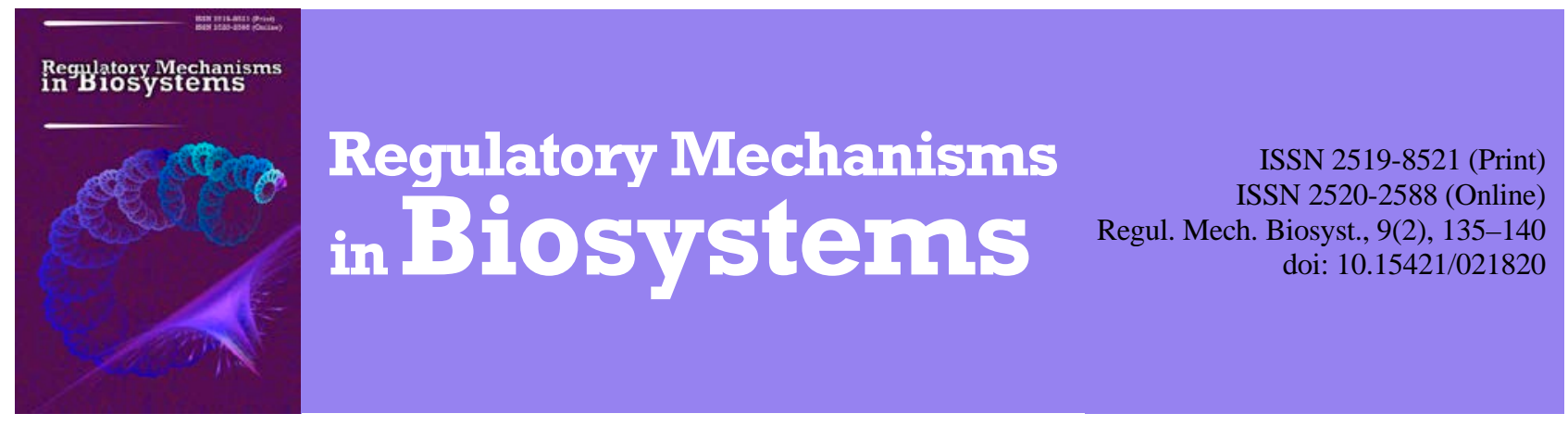

\title{
Effect of sodium chloride on oxidative stress biomarkers of the freshwater bivalve Anodonta cygnea
}

\author{
D. S. Pesnya*, A. V. Romanovsky*, Y. S. Klimova*, R. A. Fedorov*, E. S. Ivanova** \\ *Papanin Institute for Biology of Inland Waters, Borok, Russia \\ **Cherepovets State University, Cherepovets, Russia
}

Article info

Received 27.01.2018

Received in revised form 07.03.2018

Accepted 09.03.2018

Papanin Institute for Biology of Inland Waters, Russian Academy of Sciences, Borok, 152742, Russia.

Cherepovets State University, Cherepovets, 162600, Russia.

E-mail:

24pesnya@gmail.com
Pesnya, D. S., Romanovsky, A. V., Klimova, Y. S., Fedorov, R. A., \& Ivanova, E. S. (2018). Effect of sodium chloride on oxidative stress biomarkers of the freshwater bivalve Anodonta cygnea. Regulatory Mechanisms in Biosystems, 9(2), 135-140. doi:10.15421/021820

For the first time a study was conducted of the effects of the change in the concentration of sodium chloride in water on the biomarkers of oxidative stress (enzymes: catalase (CAT), glutathione reductase (GR), glutathione-S-transferase (GST), and the levels of reduced glutathione (GSH), and a marker of peroxidation lipids (LPO) - malonic dialdehyde (MDA)) in the gills of the freshwater mollusc Anodonta cygnea. Adult specimens of $A$. cygnea of both sexes with a shell length of 70-100 mm were selected for the study, a total of 36 individuals. The molluscs were collected in one of the bays on the southwestern coast of the Volga reaches of the Rybinsk Reservoir (reservoir of the cascade of the upper Volga). The molluscs were kept in the laboratory in aquariums with river water and sand collected from the place of the molluscs' collection. During the experiment, a solution of $\mathrm{NaCl} 3 \mathrm{~g} / \mathrm{l}$ in river water was introduced into the container with molluscs. Samples of molluscs' tissues were taken before application of the saline solution, 40 and 120 min after changing the salt concentration to $3 \mathrm{~g} /$, and 20 and $60 \mathrm{~min}$ after changing the $\mathrm{NaCl}$ solution to river water. The change in the concentration of $\mathrm{NaCl}$ in water $(0-3 \mathrm{~g} / \mathrm{l})$ did not affect the content of water-soluble protein in the gills of molluscs during shortterm exposure. The change in $\mathrm{NaCl}$ concentration in water caused the intensification of LPO processes in the gills of $A$. cygnea. The change in the activity of the enzymes of the antioxidant system and the increase in the concentration of GSH in A. cygnea gills, indicates their involvement in protecting freshwater molluscs from $\mathrm{NaCl}$-induced oxidative stress. The change in the functioning of the glutathione system may be a compensatory mechanism for changing the $\mathrm{NaCl}$ concentration in water. Such biomarkers of oxidative stress as malonic dialdehyde and enzymes of the antioxidant system are sensitive indicators of changes in $\mathrm{NaCl}$ concentration in water in freshwater bivalve molluscs, for example $A$. cygnea.

Keywords: antioxidant; catalase; glutathione-s-transferase; glutathione reductase; reduced glutathione; malonic dialdehyde

\section{Влияние хлорида натрия на биомаркеры окислительного стресса пресноводного двустворчатого моллюска Anodonta cygnea}

\author{
Д. С. Песня*, А. В. Романовский*, Я. С. Климова*, Р. А. Федоров*, Е. С. Иванова** \\ *Институт биологии внутренних вод имени И. Д. Папанина РАН, Борок, Россия \\ **Череповеикий государственный университет, Череповеи, Россия
}

\begin{abstract}
Впервые исследовано влияние изменения концентрации хлорида натрия в воде на биомаркеры окислительного стресса (антиоксидантные ферменты (каталаза, глутатионредуктаза, глутатион-S-трансфераза), а также уровни восстановленного глутатиона и маркера перекисного окисления липидов - малонового диальдегида в жабрах пресноводного моллюска Anodonta cygnea. Для исследований отобрали 36 взрослых особей A. cygnеа обоего пола с длиной раковины 70-100 мм. Моллюски собраны в одном из заливов юго-западного побережья Волжского плеса Рыбинского водохранилища (водохранилище каскада верхней Волги). Моллюсков содержали в лабораторных условиях в аквариумах с речной водой и песком, собранным из места их обитания. Во время эксперимента в емкости с моллюсками вносили раствор $\mathrm{NaCl}$ (3 г/л) на речной воде. Пробы тканей моллюсков отбирали до внесения солевого раствора, через 40 и 120 мин после изменения концентрации соли до 3 г/л, и через 20 и 60 мин после смены раствора $\mathrm{NaCl}$ на речную воду. Изменение концентрации $\mathrm{NaCl}$ в воде (0-3 г/л) не повлияло на содержание водорастворимого белка в жабрах моллюсков при краткосрочном воздействии. Изменение концентрации $\mathrm{NaCl}$ в воде вызвало усиление процессов перекисного окисления липидов в жабрах А. суgnеа. Изменение активности ферментов антиоксидантной системы и увеличение концентрации восстановленного глутатиона в жабрах A. суgпеа указывает на их участие в защите пресноводного моллюска от NaCl-индуцированного окислительного стресса. Изменение в функционировании глутатионовой системы может являться компенсаторным механизмом на изменение концентрации $\mathrm{NaCl}$ в воде. Такие биомаркеры оксидативного стресса как малоновый диальдегид и ферменты антиоксидантной системы являются чувствительными индикаторами изменения концентрации $\mathrm{NaCl}$ в воде у пресноводных двустворчатых моллюсков на примере $A$. cygnea.
\end{abstract}

Ключевье слова: антиоксидантная система; каталаза; глутатион-S-трансфераза; глутатионредуктаза; глутатион; малоновый диальдегид 


\section{Введение}

Молекулярный кислород $\left(\mathrm{O}_{2}\right)$ составляет основу биоэнергетики в аэробных организмах. Однако его неполное восстановление неферментативными и ферментативными процессами приводит к образованию активных форм кислорода (АФК) (Winston \& Di Giulio, 1991). В процессе эволюции у аэробных организмов выработалась антиоксидантная система (АОС), которая обезвреживает АФК и обеспечивает защиту клеток от окислительных повреждений. Таким образом, АОС играет важную роль в поддержании внутриклеточного гомеостаза (Baysoy et al., 2012).

Антиоксидантная система защиты включает в себя антиоксидантные ферменты, а также такие низкомолекулярные вещества как восстановленный глутатион (ГЛТ), некоторые витамины (Е, С и т. д.). Фермент супероксиддисмутаза восстанавливает $\mathrm{O}_{2}{ }^{-}$с образованием перекиси водорода. Каталаза, глутатионредуктазы и трансферазы участвуют в утилизации $\mathrm{H}_{2} \mathrm{O}_{2}$ (Falfushynska et al., 2012). Глутатион-S-трансфераза катализирует реакции восстановления органических пероксидов и трансформации ксенобиотиков, при этом источником водорода является восстановленный глутатион (Liu et al., 2017). В этом случае восстановленный глутатион переходит в окисленную форму. Восстанавливает его фермент глутатионредуктаза (Canesi et al., 1999). Восстановленный глутатион также обладает антиоксидантной активностью, выступая нейтрализатором АФК (Viarengo et al., 1997). Поэтому многие звенья антиоксидантной системы могут применяться как индикаторы загрязнения. Также одним из способов оценки эффективности работы системы АОС является определение концентрации продуктов перекисного окисления липидов (ПОЛ). При взаимодействии АФК с липидами клеток образуются продукты ПОЛ, такие как шиффовы основания, диеновые конъюгаты, гидроперекиси, малоновый диальдегид (рис. 1).

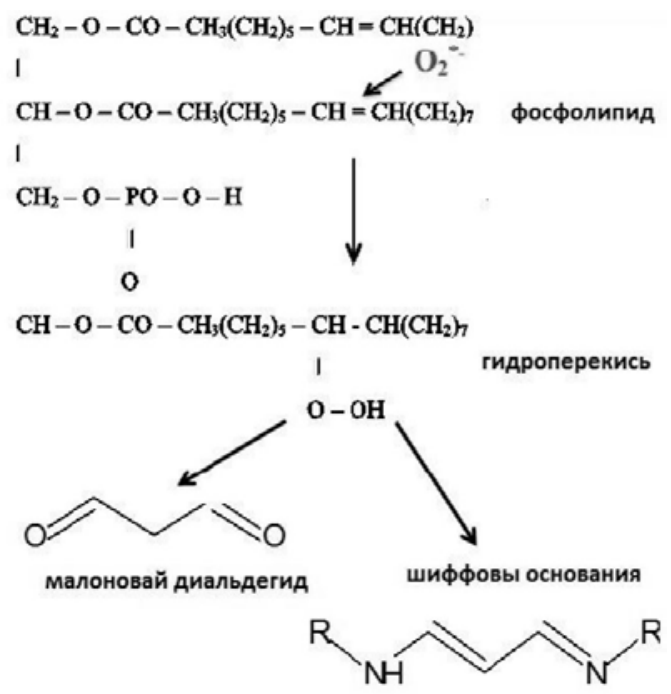

Рис. 1. Схема развития процессов образования продуктов перекисного окисления липидов

При действии различных факторов (температура, соленость, доступность кислорода, половой цикл, химическое загрязнение и т. д.) в организме изменяется функционирование биохимических регуляторных систем, что сопровождается повышенной продукцией АФК (Lushchak, 2011). Их усиленное образование может привести к развитию окислительного стресса и повреждению ДНК. Окислительный стресс характеризуется накоплением в клетке продуктов перекисного окисления липидов (ПОЛ), при одновременном уменьшении эффективности функционирования АОС. Интенсивность окислительных повреждений при этом зависит от эффективности АОС, которая поддерживает окислительно-восстановительный баланс клетки. Таким образом, если АОС не справляется с избыточной продукцией АФК, это может привести к окислительным повреждениям клеточных структур: перекисно- му окислению липидов клеточных мембран, нарушению работы ферментов, окислению структурных белков и повреждению ДНК (Halliwell \& Gutteridge, 1999). Поэтому АОС играет важную роль в адаптационном потенциале аэробных организмов (Valavanidis et al., 2006).

Соленость - важный абиотический фактор, который влияет на многие физиологические функции организма водных животных. Засоление пресноводных экосистем недавно признано серьезной угрозой здоровью этих экосистем (Beggel \& Geist, 2015). Соленость пресных водоемов может повышаться в результате антропогенного воздействия: сельскохозяйственного орошения, добычи полезных ископаемых, отходов промышленных предприятий, сточных вод и смывов соли с дорог. Зимние стоки с автомагистралей с высокой концентрацией противообледенительной соли приводят к значительному увеличению уровней солености окружающих вод (Koryak et al., 2001; Norrström, 2005). Концентрация хлоридов в северо-восточной части США достигает в городских стоках 5 г/л (Novotny et al., 2008). Изменение солености может привести к нарушению структуры экосистем, видового состава, изменению метаболизма пресноводных животных, что может в конечном итоге отразиться на их антиоксидантном статусе (Choi et al., 2008; Baysoy et al., 2012).

Униониды (Unionidae) являются одной из наиболее чувствительных к антропогенным загрязнениям групп пресноводных двустворчатых моллюсков, численность которых стремительно сокращается в Европе и Америке. Там эти виды имеют статус в зависимости от региона, от «вымерших» и «находящихся под угрозой исчезновения» до «уязвимых» (IUCN). В связи с этим важно понять причины, приводящие к сокращению их численности (Strayer et al., 2004; Geist, 2010).

Пресноводные моллюски играют важную роль в экосистемных процессах благодаря их влиянию на циклирование питательных веществ, биотурбацию и осаждение взвешенной органики (Vaughn, 2010). К сожалению, места их обитания все чаще страдают из-за стоков различных загрязнителей (Liu et al., 2017). Изменения в среде обитания приводят к быстрым изменениям в метаболизме пресноводных моллюсков на разных уровнях: биохимическом, клеточном и физиологическом. Поэтому различные представители пресноводных унионид, такие как Anodonta spp. и Unio spp., предложены в качестве чувствительных объектов в биомониторинге, биоиндикации и биотестировании (Guidi et al., 2010). Исследования выявили способность представителей рода Anodonta (на примере A. woodiana) аккумулировать микроэлементы и пестициды, а также их потенциал для обнаружения мутагенов (Liu et al., 2017). Из данных литературы известно, что униониды рода Anodonta (на примере A. imbecilis) также высокочувствительны к тяжелым металлам, как и зоопланктон (Daphnia), и более чувствительны, чем рыбы и водные насекомые (Keller \& Zam, 1991). А для Unio pictorum при сравнительно высокой чувствительности к антропогенным загрязнениям выявлена невысокая способность к аккумуляции тяжелых металлов, что следует учитывать при выборе тестового объекта для оценки биодоступности этих элементов в пресноводных экосистемах. В целом униониды являются чувствительными и удобными модельными организмами в лабораторных и полевых исследованиях (Doucet-Beaupre et al., 2010; Guidi et al., 2010).

Знание экотоксикологической значимости солености в жизни пресноводных двустворчатых моллюсков особенно важно для установления научно обоснованных пороговых значений для регуляции окружающей среды. К настоящему моменту отрицательные эффекты воздействия $\mathrm{NaCl}$ представлены в основном для североамериканских видов пресноводных моллюсков (Gillis, 2011; Pandolfo et al., 2012; Blakeslee et al., 2013; Fritts et al. 2014). Исследовано воздействие разных концентраций хлоридов на глохидии Anodonta anatina, а также влияние на скорость прикрепления глохидий к их хозяину. После 24-часовой экспозиции при концентрации хлоридов выше 727 мг/л отмечено достоверное угнетение жизнеспособности глохидий, а ЛД 50 зарегистрирована при концентрации хлоридов 2505 мг/л, что соответствует 4129 мг/л 
чистого $\mathrm{NaCl}$. Успешное присоединение глохидий к хозяину Phoxinus phoxinus отрицательно коррелировало с увеличением концентрации хлоридов и стало значительным при концентрации 2909 мг/л (Beggel \& Geist, 2015).

Повышение концентрации $\mathrm{NaCl}$ в воде приводит к снижению осмотического градиента между организмом гидробионта и средой, что сопровождается ухудшением условий диффузии воды в клетки. При приближении концентрации натрия в воде к таковой гемолимфы пресноводные моллюски начинают повышать соленость внутренней среды, что сопровождается нарастанием энергетического обмена и ЧСС (частоты сердечных сокращений). Повышение концентрации натрия в гемолимфе моллюсков происходит в пределах физиологических особенностей конкретного вида. Превышение этого предела приводит к защитно-оборонительной реакции моллюска, его изоляции от окружающей среды путем плотного закрывания створок и переходу на анаэробный обмен, что сопровождается снижением ЧСС (Martemyanov, 2011).

Для Anodonta cygnea предел толерантности к солености воды составляет около 2\% (Shkorbatov \& Starobogatov, 1990; Khlebovich, 2013). Данный вид пресноводных моллюсков имеет соленость внутренней среды около 1,7\%о и поэтому является исключением из правила Бидла, которое постулирует отсутствие в природе организмов с внутренней соленостью ниже 5\%. То обстоятельство, что пресноводные двустворчатые моллюски характеризуются исключительно низкой внутренней соленостью, не может быть объяснено большей древностью обитания этих организмов в пресных водах и требует специального исследования (Khlebovich, 2013). В экспериментах по изучению влияния солености на ЧСС быстрое повышение содержания $\mathrm{NaCl}$ в воде до 3 г/л сопровождалось повышением ЧСС (тахикардия) у А. cygnea, а более высокие концентрации (5-8 г/л) всегда приводили к снижению ЧСС (брадикардия) (Sharov \& Kholodkevich, 2015). Узкий диапазон солености около 5-8\%о носит критический характер и является универсальным барьером, при переходе через который изменяется ряд биологических свойств на разных уровнях биологической интеграции. Увеличение солености до 5-7\%о вызывает у А. cygnea закрытие створок и существенное уменьшение потребляемого кислорода (гипоксия).

Жабры являются одним из органов пресноводных двустворчатых моллюсков, ответственных за детоксикацию и аккумуляцию чужеродных веществ. При этом жабры прежде всего контактируют с веществами, содержащимися в воде, и для них показана наиболее высокая активность ферментов АОC (Prevodnik et al., 2007). За последние годы накопилось много данных о влиянии загрязнителей на особенности оксидативного стресса у некоторых видов пресноводных моллюсков. При оценке биологических эффектов загрязнителей в полевых условиях следует учитывать наложение абиотических факторов (сезонность, течения, соленость). Это приводит к разнонаправленной реакции антиоксидантной системы, что может вызвать сложности в интерпретации результатов полевых исследований (Falfushynska et al., 2010). Участие абиотических факторов в окислительном стрессе у пресноводных моллюсков исследовано недостаточно. В литературе также мало данных и о влиянии изменений солености на показатели антиоксидантной системы у пресноводных двустворчатых моллюсков (Binelli et al., 2015).

Цель данной работы - исследование влияния изменения концентрации хлорида натрия в воде на интенсивность образования малонового диальдегида, активность ферментов антиоксидантной системы в жабрах пресноводного двустворчатого моллюска A. cygnea. Данный вид хорошо подходит для изучения биомаркеров окислительного стресса, благодаря его высокой чувствительности (Robillard et al., 2003).

\section{Материал и методы исследований}

Исследования проводили на взрослых особях А. cygnea с длиной раковины 70-100 мм. Животные были собраны в одном из заливов юго-западного побережья Волжского плеса Рыбинского водохранилища (одного из водохранилищ каскада верхней Волги) вблизи пос. Борок $\left(58^{\circ} 03^{\prime} 45^{\prime \prime}\right.$ с. ш. $38^{\circ} 14^{\prime} 23^{\prime \prime}$ в. д.) в сентябре 2012 г. (рис. 2).

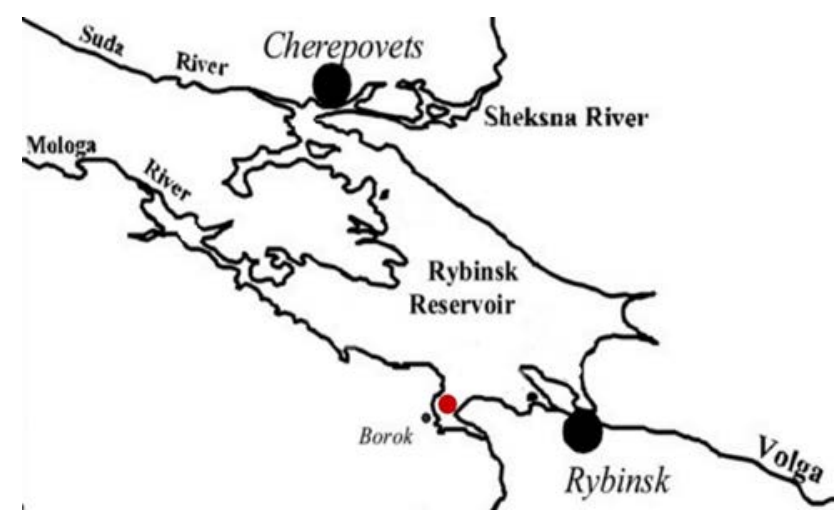

Рис. 2. Схема Рыбинского водохранилища: красной точкой отмечено место сбора моллюсков

В течение 30 мин после отлова моллюсков доставляли в лабораторию в пластиковых изотермических контейнерах объемом 10 л. После вылова и транспортировки в лабораторию моллюсков в течение двух недель для их адаптации содержали в статических условиях в аквариуме со 150 л речной воды и песчаным грунтом, собранным в месте их обитания, с заменой 50 л воды каждые 2 суток, которая подавалась постепенно через резиновый шланг. Во время частичной смены воды моллюсков не извлекали из аквариума, чтобы не вызвать закрытие створок. Сливали воду через отверстие, закрывающееся резиновой пробкой, в углу на дне аквариума. Условия содержания следующие: содержание растворенного кислорода на уровне насыщения за счет принудительной аэрации воды, температура воды $-21^{\circ} \mathrm{C}, \mathrm{pH}-7$. Моллюсков кормили два раза в неделю хлореллой из лабораторной культуры с добавлением кормовых дрожжей, в соотношении 50 г сухих дрожжей и 50 мл хлореллы на одно кормление. Хлореллу концентрировали центрифугированием и промывали дистиллированной водой.

В эксперименте использовано 36 особей. Во время опыта в емкости с моллюсками вносили раствор $\mathrm{NaCl}$ (х. ч.) 3 г/л на речной воде. Раствор вносили через резиновую трубку, равномерно и осторожно распределяя по всему объему воды в аквариуме. После повышения концентрации соли в воде и смены воды створки у моллюсков оставались открытыми. Отбирали пробы по схеме, представленной в таблице, используя выборки по 6 моллюсков. Для унификации условий отбора проб и минимизации изменений биохимических параметров каждую группу моллюсков отбирали одновременно и сразу помещали в жидкий азот (температура -$\left.196^{\circ} \mathrm{C}\right)$ на 10 мин. Для последующего анализа использовали жабры. Препарировали при $4{ }^{\circ} \mathrm{C}$. Образцы тканей жабр упаковывали в пластиковые пробирки и хранили в жидком азоте до проведения биохимического анализа.

Исследованы биомаркеры окислительного стресса, такие как антиоксидантные ферменты: каталаза (САТ) - пероксид : пероксид оксидоредуктаза (ЕС 1.11.1.6), которая участвует в утилизации $\mathrm{H}_{2} \mathrm{O}_{2}$; глутатионредуктаза (GR) - НАД(Ф)Н: окисленный глутатион оксидоредуктаза (ЕС 1.8.1.7), который восстанавливает окисленный глутатион; глутатион-S-трансфераза (GST) (EC 2.5.1.18), которая принимает участие в нейтрализации органических гидроперекисей и является ферментом II фазы биотрансформации ксенобиотиков (Halliwell \& Gutteridge, 1999), а также уровень низкомолекулярного антиоксиданта - восстановленного глутатиона (GSH), и маркер перекисного окисления липидов (ПОЛ) - малоновый диальдегид (MDA) (Faria et al., 2009).

Для биохимического анализа навеску ткани, к которой добавляли $0,1 \mathrm{M}$ фосфатный буфер, $\mathrm{pH}$ 7,5, в объемном соотношении $1: 4$, используя диспергатор биологических тканей IKA T10 Ultra Turax (Laboratory Equipment, Germany). Для получения суперна- 
танта гомогенат центрифугировали при $15000 \mathrm{~g} \mathrm{и} \mathrm{t}=4{ }^{\circ} \mathrm{C}$ в течение 30 мин (Місrо 22 R, Германия).

Все измерения концентрации и активности ферментов проводили на аналитическом спектрофотометре Lambda 25 (Perkin Elmer, USA). В цельном гомогенате определяли содержание MDA - по реакции с 2-тиобарбитуровой кислотой при $\lambda=532$ нм и GSH по реакции с 5,5'-дитио(бис)-2-нитробензойной кислотой (5,5'-dithiobis-2-nitrobenzoic acid) при $\lambda=412$ нм. В супернатанте опеределяли активность ферментов: САТ - по убыли перекиси водорода при $25^{\circ} \mathrm{C}$ и длине волны $\lambda=410$ нм, GR - по убыли NADPH при $25^{\circ} \mathrm{C}$ и $\lambda=349$ нм, GST - по реакции с 1-хлор-2,4-динитробензолом (1-chloro-2,4-dinitrobenzene) при $27^{\circ} \mathrm{C}$ и $\lambda=349$ нм (Klimova et al., 2017). Концентрацию белка в пробах измеряли методом Брэдфорд с бычьим сывороточным альбумином в качестве стандарта. Температура инкубационной среды при определении активности ферментов поддерживалась на уровне $25,0 \pm 0,5{ }^{\circ} \mathrm{C}$ (Morozov et al., 2012).

Результаты представлены в виде среднего и стандартной ошибки ( $\mathrm{x} \pm \mathrm{SE}, \mathrm{n}=6)$. Достоверность различий между выборками оценивали методом однофакторного дисперсионного анализа (ANOVA), использовали U-критерий Манна-Уитни. Различия считали достоверными при $\mathrm{P}=0,05$. Объем выборочных совокупностей составил 6 особей на каждую экспериментальную группу. В таблице 1 под значениями биомаркеров приведены данные процентного изменения показателей от контрольного уровня.

\section{Результаты}

Сравнение двух опытных групп животных, которые находились в условиях воздействия соли в концентрации 3 г/л при экспозиции 40 и 120 мин, не выявили достоверных отличий биомаркеров от контрольных значений. При этом можно отметить следующие тенденции в изменении биомаркеров: концентрации MDA и GSH, а также активность GR возрастают, а активность GST и CAT уменьшается (табл. 1).

\section{Таблица 1}

Значения параметров перекисного окисления липидов (\%) и антиоксидантной системы в жабрах Anodonta cygnea при действии солевого стресса в эксперименте $(\mathrm{x} \pm \mathrm{SE}, \mathrm{n}=6)$

\begin{tabular}{|c|c|c|c|c|c|c|}
\hline \multirow{2}{*}{$\begin{array}{l}\text { Экс- } \\
\text { пози- } \\
\text { ция, } \\
\text { мин }\end{array}$} & \multirow{2}{*}{$\begin{array}{c}\text { Водораст- } \\
\text { воримый } \\
\text { белок, } \\
\text { мкг/мг }\end{array}$} & MDA & GSH & GR & GST & CAT \\
\hline & & \multicolumn{2}{|c|}{ пкмоль/мкг белка } & \multicolumn{3}{|c|}{ нмоль/мкг белка } \\
\hline \multicolumn{7}{|c|}{ До внесения $\mathrm{NaCl}$} \\
\hline 0 & $334,8 \pm 39,3$ & $1,3 \pm 0,2$ & $\begin{array}{r}3,9 \pm 0,5 \\
10\end{array}$ & $\begin{array}{l}1,8 \pm 0,6 \\
, 0\end{array}$ & & \\
\hline \multicolumn{7}{|c|}{ бовавения $\mathrm{NaCl}$} \\
\hline 40 & $\begin{array}{c}347,4 \pm 53,2 \\
103,8\end{array}$ & $\begin{array}{c}1,7 \pm 0,2 \\
130,8\end{array}$ & & & & $\begin{array}{c}36,8 \pm 4,1 \\
91,1\end{array}$ \\
\hline 120 & $\begin{array}{c}405,7 \pm 47,2 \\
121,2\end{array}$ & $\begin{array}{c}1,5 \pm 0,2 \\
115,4\end{array}$ & & $\begin{array}{c}3,2 \pm 0,6 \\
178,8\end{array}$ & $\begin{array}{c}3,1 \pm 0,5 \\
91,2\end{array}$ & $\begin{array}{c}34,4 \pm 3,9 \\
85,1\end{array}$ \\
\hline \multicolumn{7}{|c|}{ После смены раствора $\mathrm{NaCl}$ на отстоянную речную воду } \\
\hline 20 & $\begin{array}{c}352,6 \pm 31,4 \\
105,3\end{array}$ & $\begin{array}{c}2,0 \pm 0,9^{*} \\
153,8\end{array}$ & $\begin{array}{c}5,2 \pm 0,6 \\
132,3\end{array}$ & $\begin{array}{c}2,8 \pm 0,5 \\
155,5\end{array}$ & $\begin{array}{c}1,6 \pm 0,2^{*} \\
47,1\end{array}$ & $\begin{array}{c}38,8 \pm 3,1 \\
96,0\end{array}$ \\
\hline 60 & $\begin{array}{c}435,9 \pm 26,6 \\
130,2\end{array}$ & $\begin{array}{c}1,6 \pm 0,1 \\
123,1\end{array}$ & $\begin{array}{c}5,0 \pm 0,3 \\
128,2\end{array}$ & $\begin{array}{c}3,3 \pm 0,7 \\
183,3\end{array}$ & $\begin{array}{c}2,5 \pm 0,3 \\
73,5\end{array}$ & $\begin{array}{c}28,6 \pm 1,8^{*} \\
70,8\end{array}$ \\
\hline 120 & $\begin{array}{c}382,1 \pm 24,6 \\
114,1\end{array}$ & $\begin{array}{c}1,6 \pm 0,2 \\
123,1\end{array}$ & $\begin{array}{c}6,1 \pm 0,7^{*} \\
156,4\end{array}$ & $\begin{array}{c}4,3 \pm 1,0^{*} \\
238,9\end{array}$ & $\begin{array}{c}2,2 \pm 0,4 \\
64,7\end{array}$ & $\begin{array}{c}32,9 \pm 3,2 \\
81,4\end{array}$ \\
\hline
\end{tabular}

Примечание: * - обозначает достоверное отличие от фонового варианта, т.е. до внесения хлорида натрия.

После смены воды с соленой на речную при экспозициях 20, 60 и 120 мин зарегистрировано достоверное изменение уровня биохимических показателей. Так через 20 мин после смены воды отмечается достоверное увеличение концентрации MDA в 1,5 раза и уменьшение активности GST в 2 раза по сравнению с контрольным уровнем. Через 60 мин зарегистрировано достоверное уменьшение активности САТ при отсутствии достоверных изменений других показателей. Через 120 мин отмечено достоверное увеличение концентрации GSH в 1,5 раза и активности GR более чем в два раза по сравнению с контрольными значениями, в то время как значения остальных показателей достоверно не отличаются от контрольных.

\section{Обсуждение}

При концентрации соли 3 г/л в воде повышается соленость внутренней среды моллюска A. cygnea (путем увеличения концентрации натрия в гемолимфе), что сопровождается повышением энергетического обмена и ЧСС. При такой концентрации соли в воде у моллюска еще не наступает таких последствий, как закрытие створок и гипоксия, которые отмечаются при концентрации соли 5-8 г/л (Guidi et al., 2010; Binelli et al., 2015). В настоящем эксперименте выявлено, что воздействие $\mathrm{NaCl}$ в концентрации 3 г/л у A. cygnea на биохимическом уровне приводит к повышению концентрации MDA, ключевого продукта ПОЛ. У двустворчатых моллюсков определение концентрации MDA используется как чувствительный показатель качества воды в гидроэкосистемах (Fernandez et al., 2010). У Scylla serrata при высокой солености $35 \%$ и $17 \%$ отмечаются значительно более высокие уровни перекисного окисления липидов по сравнению с более низкой соленостью 10\%. При этом активность антиоксидантных ферментов GR, SOD, CAT, GPx, наоборот, в целом более высокая при солености $10 \%$, чем при $17 \%$ и $35 \%$. Это показывает, что высокая соленость 35\%о индуцирует более значительный окислительный стресс, чем более низкие солености (Paital \& Chainy, 2010). Повышение солености воды способно повлиять на биодоступность и увеличение токсичности тяжелых металлов, которые могут конкурировать с ионами металлов при образовании биомолекул. Так, в одном из исследований зарегистрировано отрицательное влияние на темпы роста популяции $B$. rotundiformis совместного действия изменения температуры, повышения солености и как результат увеличения степени токсичности ионов меди (Gama-Flores et al., 2005). В исследовании на Penaeus monodon показано, что совместное действие пестицида дельтаметрина, солености и температуры способно индуцировать более выраженный окислительный стресс. Это исследование показало, что при анализе биомаркеров окислительного стресса следует учитывать взаимодействие между абиотическими факторами и такими поллютантами как пестициды (Tu et al., 2012). В другом исследовании установлено, что у двустворчатого моллюска Unio tumidus изменение концентрации MDA напрямую коррелирует с концентрацией 8-оксо-7,8-дигидро-2'деоксигуанозина, продукта окисления ДНК (Charissou et al., 2004). Таким образом, повышение уровня MDA может сопровождаться окислительным повреждением ДНК.

Изменение концентрации хлорида натрия в настоящем эксперименте привело к достоверному уменьшению активности САТ в жабрах. Понижение активности САТ может быть связано с появлением супероксидных радикалов, которые, как известно, ингибируют активность каталазы (Koprucu et al., 2008). Аналогичное изменение активности САТ описано у Acipenser naccarii, выращенного в пресной воде, а затем помещенного в морскую воду (35\%) (Martínez-Álvarez et al., 2002). В условиях эксперимента пестицид дельтаметрин вызывал значительное снижение активности САТ у пресноводного моллюска Unio elongatulus eucirrus (Koprucu et al., 2008). В другом исследовании обнаружено, что при изучении влияния выбросов пестицидов в окружающую среду среди ферментов АОС у А. cygnea активность каталазы не коррелировала со степенью загрязнения пестицидами, а отражала естественные вариации в годовом физиологическом цикле вида и была сильно подвержена влиянию абиотических факторов (Robillard et al., 2003). CAT, так же как и MDA, - маркер оксидативных поражений, причинами которых могут быть и поллютанты, и изменения солености (Fernandez et al., 2010).

Нами зарегистрировано понижение активности GST в жабрах A. cygnea, что указывает на восприимчивость данного биомаркера к изменениям солености. Глутатион-S-трансфераза является ферментом, катализирующим антиоксидантный метаболизм тиоловых 
соединений, что, в свою очередь, защищает клетку от электрофилов, повреждения свободными радикалами и окислительного стресса. Значительное уменышение активности GST может привести к формированию реактивных форм кислорода (ROS), образованию высокотоксичных гидроксильных радикалов и целому каскаду реакций, повреждающих клеточную мембрану, то есть повышению концентрации ПОЛ (Limón-Pacheco \& Gonsebatt, 2009). У A. cygnea данный биомаркер чувствителен к антропогенным загрязнениям и выбросам ксенобиотиков (Falfuchynska et al., 2010; Falfuchynska et al., 2012). В исследовании влияния изменений солености на Paralichthys olivaceus зарегистрировано изменение экспрессии mRNA глутатион-S-трансферазы и глутатионовой пероксидазы, что привело к выводу о том, что данные ферменты играют важную роль в детоксикации АФК и могут быть индикаторами окислительного стресса, индуцированного изменениями солености (Choi et al., 2008).

Восстановленный глутатион связывает металлы, СО3 (стойкие органические загрязнители) и улавливает ROS, поэтому coставляет первую линию защиты от их токсического воздействия. Как видно из таблицы 1, увеличение концентрации GSH соответствует повышению активности GR. Известно, что GR опосредованно участвует в инактивации ROS. GR восстанавливает окисленный глутатион (GSSG) в NADPH-зависимой реакции, поддерживая важный для клеточного гомеостаза и работы других ферментов баланс GSSG/GSH, и поэтому играет важную роль в системе антиоксидантной защиты клетки (Fernandez et al., 2010). Достоверное увеличение значений данных показателей указывает на то, что GSH может являться важным звеном AOC в защите от $\mathrm{NaCl}$-индуцированного стресса.

Тенденция повышения уровня GSH обнаружена у M. galloprovincialis на загрязненных станциях в естественной среде, в результате накопления в моллюсках Cr, Fe и Mn (Regoli et al., 2004). В других работах на моллюсках M. galloprovincialis и рыбах Abramis brama и Dicentrarchus labrax отмечено уменьшение концентрации GSH в результате влияния тяжелых металлов и СO3 в полевых и лабораторных условиях (Canesi et al., 1999; Morozov et al., 2012). В некоторых исследованиях сообщалось о кратковременном повышении концентрации GSH и последующем уменышении у разных видов растений и животных. В результате анализа данных литературы и результатов настоящего исследования можно предположить, что изменение концентрации GSH зависит от типа загрязнителя и продолжительности экспозиции. В наших лабораторных экспериментах краткосрочное изменение концентрации хлорида натрия в воде приводило к увеличению уровня GSH и повышению активности GR у A. cygnea, что может являться адаптивной реакцией. Так как эндогенный синтез глутатиона осуществляется ферментами с-глутамин-цистеинсинтетаза и глутатионсинтетазой, a GR восстанавливает его окисленную форму, можно предположить, что на момент эксперимента данные ферменты за счет совместного функционирования обеспечивали достаточное возобновление восстановленного глутатиона (GSH) в тканях моллюсков, при повышенных конщентрациях хлорида натрия в окружающей среде (Klimova et al., 2017).

\section{Выводы}

Исследовано влияние краткосрочного изменения конщентрации хлорида натрия в воде (концентрация $\mathrm{NaCl}-3$ г/л) на биохимические маркеры окислительного стресса пресноводного моллюска A. cygnea. Изменение концентрации хлорида натрия до 3 г/л не влияет на концентрацию водорастворимого белка. Изменение концентрации хлорида натрия повышает концентрацию продуктов перекисного окисления липидов в жабрах A. cygnea, что указывает на вероятное участие окислительного стресса в механизмах токсичности хлорида натрия у пресноводных двустворчатых моллюсков. Изменение активности ферментов антиоксидантной системы и увеличение концентрации GSH в жабрах A. cygnea, указывает на их участие в защите пресноводного моллюска от

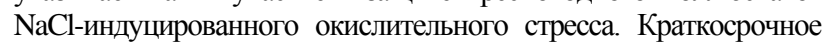

изменение концентрации хлорида натрия в воде вызвало усиление процессов ПОЛ у А. cygnea. Это предполагает неспособность АОС устранять избыток ROS, что приводит к окислению липидов. Но при этом степень оксидативных повреждений не настолько высока, чтобы инактивировать ферменты антиоксидантной системы. В результате изменилось функционирование глутатионовой системы, что может являться компенсаторным механизмом на изменение концентрации хлорида натрия в воде. Таким образом, биомаркеры окислительного стресса пресноводных двустворчатых моллюсков $A$. cygnea являются чувствительными показателями изменения концентрации $\mathrm{NaCl}$ в воде.

Мы признательны В. Б. Вербицкому, С. Быковой, Г. М. Чуйко, А. Н. Шарову и С. В. Холодкевич. Источник бюджетного финансирования AAAA-A18-118012690101-2.

\section{References}

Baysoy, E., Atli, G., Gürler, C. Ö., Dogan, Z., Eroglu, A., Kocalar, K., \& Canli, M. (2012). The effects of increased freshwater salinity in the biodisponibility of metals $(\mathrm{Cr}, \mathrm{Pb})$ and effects on antioxidant systems of Oreochromis niloticus. Ecotoxicology and Environmental Safety, 34(84), 249-253.

Beggel, S., \& Geist, J. (2015). Acute effects of salinity exposure on glochidia viability and host infection of the freshwater mussel Anodonta anatina (Linnaeus, 1758). Science of the Total Environment, 502, 659-665.

Binelli, A., Torre, C. D., Magni, S., \& Parolini, M. (2015). Does zebra mussel (Dreissena polymorpha) represent the freshwater counterpart of Mytilus in ecotoxicological studies? A critical review. Environmental Pollution, 196, 386-403.

Blakeslee, C. J., Galbraith, H. S., Robertson, L. S., \& White, B. S. J. (2013). The effects of salinity exposure on multiple life stages of a common freshwater mussel, Elliptio complanata. Environmental Toxicology and Chemistry, 32(12), 2849-2854.

Canesi, L., Viarengo, A., Leonzio, C., Filippelli, M., \& Gallo, G. (1999). Heavy metals and glutathione metabolism in mussel tissues. Aquatic Toxicology, 46(1), 67-76.

Charissou, A. M., Cossu-Leguille, C., \& Vasseur, P. (2004). Relationship between two oxidative stress biomarkers, malondialdehyde and 8-0xo-7,8-dihydro-2'deoxyguanosine, in the freshwater bivalve Unio tumidus. Science of The Total Environment, 322, 109-122.

Choi, C. Y., An, K. W., \& An, M. I. (2008). Molecular characterization and mRNA expression of glutathione peroxidase and glutathione S-transferase during osmotic stress in olive flounder (Paralichthys olivaceus). Comparative Biochemistry and Physiology, Part A, 149, 330-337.

Doucet-Beaupre, H., Dubé, C., Breton, S., Pörtner, H. O., \& Blier, P. U. (2010). Thermal sensitivity of metabolic enzymes in subarctic and temperate freshwater mussels (Bivalvia: Unionoida). Joumal of Thermal Biology, 35(1), 11-20.

Falfushynska, H. I., Gnatyshyna, L. L., Farkas, A., Vehovszky, A., Gyori, J., \& Stoliar, O. B. (2010). Vulnerability of biomarkers in the indigenous mollusk Anodonta cygnea to spontaneous pollution in a transition country. Chemosphere, 81(10), 1342-1351.

Falfushynska, H. I., Gnatyshyna, L. L., Golubev, A. P., \& Stoliar, O. B. (2012). Main partitioning criteria for the characterization of the health status in the freshwater mussel Anodonta cygnea from spontaneously polluted area in Western Ukraine. Environmental Toxicology, 27(8), 485-494.

Faria, M., Carrasco, L., Diez, S., Riva, M. C., Bayona, J. M., \& Barata, C. (2009) Multibiomarker responses in the freshwater mussel Dreissena polymorpha exposed to polychlorobiphenyls and metals. Comparative Biochemistry and Physiology, Part C, 149, 281- 288.

Fernandez, B., Campillo, J. A., Martinez-Gomez, C., \& Benedicto, J. (2010). Antioxidant responses in gills of mussel (Mytilus galloprovincialis) as biomarkers of environmental stress along the Spanish Mediterranean coast. Aquatic Toxicology, 99, 186-197.

Fritts, A. K., Bamhart, C., Bradley, M., Liu, N., Cope, W. G., Hammer, E., \& Bringolf, R. B. (2014). Assessment of toxicity test endpoints for freshwater mussel larvae (glochidia). Environmental Toxicology and Chemistry, 33(1), 199-207.

Gama-Flores, J. L., Sarma, S. S. S., \& Nandini, S. (2005). Interaction among copper toxicity, temperature and salinity on the population dynamics of Brachionus rotundiformis (Rotifera). Hydrobiologia, 546, 559-568.

Geist, J. (2010). Strategies for the conservation of endangered freshwater pearl mussels (Margaritifera margaritifera L.): A synthesis of conservation genetics and ecology. Hydrobiologia, 644, 69-88.

Gillis, P. (2011). Assessing the toxicity of sodium chloride to the glochidia of freshwater mussels: Implications for salinization of surface waters. Environmental Pollution, 159, 1702-1708. 
Guidi, P., Frenzilli, G., Benedetti, M., Bernardeschi, M., Falleni, A., Fattorini, D., Regoli, F., Scarcelli, V., \& Nigroa, M. (2010). Antioxidant, genotoxic and lysosomal biomarkers in the freshwater bivalve (Unio pictorum) transplanted in a metal polluted river basin. Aquatic Toxicology, 100, 75-83.

Halliwell, B., \& Gutteridge, J. M. C. (1999). Free radicals in biology and medicine. Oxford University Press, Oxford.

Keller, E. A., \& Zam, S. G. (1999). The acute toxicity of selected metals to the freshwater mussel, Anodonta imbecilis. Toxicology and Chemistry, 10(4), 539-546.

Khlebovich, V. V. (2013). Kriticheskaya solenost' - gomeostaz - ustoichivoe razvitie [Critical salinity - homeostasis - sustainable development]. Trudy Zoologicheskogo Instituta RAN, Prilojenie, 3, 3-6 (in Russian).

Klimova, Y. S., Chuiko, G. M., Gapeeva, M. V., \& Pesnya, D. S. (2017). The use of biomarkers of oxidative stress in zebra mussel Dreissena polymorpha (Pallas, 1771) for chronic anthropogenic pollution assessment of the Rybinsk Reservoir. Contemporary Problems of Ecology, 24(2), 210-217.

Koprucu, S. S., Yonar, E., \& Seker, E. (2008). Effects of deltamethrin on antioxidant status and oxidative stress biomarkers in freshwater mussel, Unio elongatulus eucirrus. Bulletin of Environmental Contamination and Toxicology, 81, 253-257.

Koryak, M., Stafford, L. J., Reilly, R. J., \& Magnuson, P. M. (2001). Highway deicing salt runoff events and major ion concentrations along a small urban stream. Journal of Freshwater Ecology, 16(1), 125-134.

Limón-Pacheco, J., \& Gonsebatt, M. E. (2009). The role of antioxidants and antioxidant-related enzymes in protective responses to environmentally induced oxidative stress. Mutation Research, 674, 137-147.

Liu, Q., Shang, X., Ma, Y., Xia, X., Xue, S., Hua, C., Liang, G., Yao, L., \& Guo, L. (2017). Isolation and characterization of two glutathione S-transferases from freshwater bivalve Anodonta woodiana: Chronic effects of pentachlorophenol on gene expression profiles. Fish and Shellfish Immunology, 64, 339-351.

Lushchak, V. I. (2011). Environmentally induced oxidative stress in aquatic animals. Aquatic Toxicology, 101, 13-30.

Martemyanov, V. I. (2011). Influence of environmental mineral composition on the indices of water-salt metabolism in Dreissena polymorpha Pallas introduced to Rybinsk Reservoir. Russian Joumal of Biological Invasions, 2, 120-134.

Martínez-Álvarez, R. M., Hidalgo, M. C., Domezain, A., Morales, A. E., GarcíaGallego, M., \& Sanz, A. (2002). Physiological changes of sturgeon Acipenser naccarii caused by increasing environmental salinity. The Journal of Experimental Biology, 205, 3699-3706.

Morozov, A. A., Chuiko, G. M., \& Brodskii, E. S. (2012). Functional state of the liver antioxidant system of the Bream Abramis brama (L.) from Rybinsk reservoir regions with different anthropogenic loads. Inland Water Biology, 5(1), 147-152.

Norrstrom, A. C. (2005). Metal mobility by de-icing salt from an infiltration trench for highway runoff. Applied Geochemistry, 20(10), 1907-1919.

Novotny, E. V., Murphy, D., \& Stefan, H. G. (2008). Increase of urban lake salinity by road deicing salt. Science of the Total Environment, 406, 131-144.
Paital, B., \& Chainy, G. B. N. (2010). Antioxidant defenses and oxidative stress parameters in tissues of mud crab (Scylla serrata) with reference to changing salinity. Comparative Biochemistry and Physiology, Part C, 151, 142-151.

Pandolfo, T. J., Cope, W. G., Young, G. B., Jones, J. W., Hua, D., \& Lingenfelser, S. F. (2012). Acute effects of road salts and associated cyanide compounds on the early life stages of the unionid mussel Villosa iris. Environmental Toxicology and Chemistry, 31(8), 1801-1806.

Prevodnik, A., Gardestrom, J., Lilja, K., Elfwing, T., McDonagh, B., Petrovi, N., Tedengren, M., Sheehan, D., \& Bollner, T. (2007). Oxidative stress in response to xenobiotics in the blue mussel Mytilus edulis L.: Evidence for variation along a natural salinity gradient of the Baltic Sea. Aquatic Toxicology, 82, 63-71.

Regoli, F., Frenzilli, G., Bocchetti, R., Annarumma, F., Scarcelli, V., Fattorini, D., \& Nigro, M. (2004). Time-course variations of oxyradical metabolism, DNA integrity and lysosomal stability in mussels, Mytilus galloprovincialis, during a field translocation experiment. Aquatic Toxicology, 68, 167-178.

Robillard, S., Beauchamp, G., \& Laulier, M. (2003). The role of abiotic factors and pesticide levels on enzymatic activity in the freshwater mussel Anodonta cygnea at three different exposure sites. Comparative Biochemistry and Physiology, Part C, 135(1), 49-59.

Sharov, A. N., \& Kholodkevich, S. V. (2015). O nekotoryh osobennostyah ispol'zovaniya presnovodnyh dvustvorchatyh molluskov pri provedenii ecotoksikologicheskih issledovaniy na osnove monitoringa ih kardioritma volokonno-opticheskim metodom [Some features of using heart rate monitoring of freshwater bivalve molluscs with a fiber-optical method for ecotoxicological research]. Principy Ecologii, 2, 21-28 (in Russian).

Shkorbatov, G. L., \& Starobogatov, Y. I. (1990). Metody izucheniya dvustvorchatyh molluskov [Method of investigation of bivalves]. Trudy Zoologicheskogo Insituta AN SSSR, 219, 208 (in Russian).

Strayer, D. L., Downing, J. A., Haag, W. R., King, T. L., Layzer, J. B., Newton, T. J., \& Nichols, J. S. (2004). Changing perspectives on pearly mussels, North America's most imperiled animals. Bioscience, 54(1), 429-439.

Tu, H. T., Silvestre, F., Meulder, B. D., Thome, J.-P., Phuong, N. T., \& Kestemont, P. (2012). Combined effects of deltamethrin, temperature and salinity on oxidative stress biomarkers and acetylcholinesterase activity in the black tiger shrimp (Penaeus monodon). Chemosphere, 86, 83-91.

Valavanidis, A., Vlahogianni, T., Dassenakis, M., \& Scoullos, M. (2006). Molecular biomarkers of oxidative stress in aquatic organisms in relation to toxic environmental pollutants. Ecotoxicology and Environmental Safety, 64, 178-189.

Vaughn, C. C. (2010). Biodiversity losses and ecosystem function in freshwaters: Emerging conclusions and research directions. Bioscience, 60, 25-35.

Viarengo, A., Bettella, E., Fabbri, R., Burlando, B., \& Lafaurie, M. (1997). Heavy metal inhibition of EROD activity in liver micomes from the Bass Dicentrarchus fabrax exposed to organic xenobiotics: Role of GSH in the reduction of heavy metal effects. Marine Environmental Research, 44(1), 1-11.

Winston, G. W., \& Di Giulio, R. T. (1991). Prooxidant and antioxidant mechanisms in aquatic organisms. Aquatic Toxicology, 19, 137-161. 